\title{
CARACTERIZAÇÃO GEOMORFOLÓGICA E OCUPAÇÃO ANTRÓPICA DE ZONAS COSTEIRAS: O CASO DA PONTA DO SEIXAS, LITORAL DA PARAÍBA - BRASIL
}

Alexandre dos Santos Souza ${ }^{1}$ Max Furrier Furrier ${ }^{2}$

RESUMO: O presente trabalho tem por objetivo fazer uma caracterização físico-ambiental de um marco geográfico do litoral brasileiro compreendido pela Ponta do Seixas, ponto mais oriental das Américas, localizado no estado da Paraíba. Nessa zona costeira (como em outros pontos do litoral paraibano e brasileiro), os processos modeladores naturais, atrelados ao uso e ocupação do solo por atividades antrópicas desenvolvidas irregularmente, têm acelerado os processos erosivos e a degradação da paisagem local. A análise da área demonstrou a eminente necessidade de implantação de medidas técnicas que promovam a conservação da paisagem. Entre as implicações da ocupação desse espaço costeiro, averiguou-se como a evolução da erosão na linha praial tem provocado graves danos socioeconômicos e paisagísticos. Outra característica dessa zona litorânea são os elementos da infraestrutura civil, construídos, em sua maioria, sobre a área limítrofe da berma, em trechos onde se faz sentir a influência da maré, fato que fere a legislação ambiental vigente no Brasil e contribui visivelmente com a degradação de um espaço de relevante representatividade geográfica.

Palavras-chave: Ponta do Seixas; erosão costeira; tabuleiros costeiros; degradação ambiental.

\section{GEOMORPHOLOGICAL CHARACTERIZATION AND ANTHROPIC OCCUPATION OF COASTAL ZONES: THE PONTA DO SEIXAS CASE, PARAÍBA'S COAST - BRAZIL}

ABSTRACT: This paper aims to make a physical and environmental characterization of a geographic landmark of the Brazilian cost, comprehended by Ponta do Seixas, the easternmost point of the Americas, located in the state of Paraiba. In this coastal zone (as in other points of the coast of Paraiba and Brazil), the natural modelers processes, linked to the use and occupation of land from anthropic activities irregularly developed, have accelerated the erosion and degradation of the local landscape. The analysis of the area showed the imminent need to implement technical measures that promote the landscape conservation. Among the implications of the occupation of this coastal area, it was examined how the evolution of erosion in praial line has caused serious socioeconomic and landscape damage. Another characteristic of this coastal area are the elements of civil infrastructure, built mostly on the border area of the berm, in stretches where it is felt the influence of the tide, a fact that infringes the current environmental regulations in Brazil and contributes visibly to the degradation of an area of relevant geographic representation.

Keywords: Ponta do Seixas; coastal erosion; coastal tablelands; environmental degradation.

1. Universidade Federal da Paraíba (alesougeo@gmail.com).

2. Universidade Federal da Paraíba (max.furrier@hotmail.com). 


\section{INTRODUÇÃO}

Nas últimas décadas, as áreas costeiras do Brasil têm sido palco de inúmeros problemas, os quais têm demonstrado, sobre vários aspetos, o quanto esses ambientes são instáveis, dinâmicos e susceptíveis a alterações que incidem em danos de ordem socioambiental. Tais efeitos, que passam a se manifestar na paisagem por meio da correlação entre zonas de vulnerabilidade e suscetibilidade, não foram ou não são, na maioria dos casos, considerados durante o processo de ocupação antrópica, fato que traz consigo agravantes que incidem negativamente sobre os planos de gerenciamento e conservação da paisagem.

No caso da Ponta do Seixas, averígua-se que esse ambiente costeiro tem evidenciado, nos últimos anos, uma série de problemas comuns às zonas litorâneas, entre os quais podem-se elencar: erosão costeira, degradação da vegetação nativa e ocupação irregular da orla praial por ação antrópica.

Os ambientes costeiros são terrenos propícios a intensa especulação imobiliária e turismo, sobretudo em função dos atrativos de recreação que esses espaços oferecem. Nessa perspectiva, torna-se de grande importância a implantação de ações adequadas de planejamento e conservação, visando mitigar os processos que provocam a degradação desses espaços, haja vista que representam perímetros suscetíveis aos processos predatórios.

Nesse contexto, por constituírem faixas limítrofes entre os continentes e os oceanos, as regiões costeiras passam a constituir áreas onde ocorre intenso intercâmbio de energia e matéria da crosta terrestre. Essas regiões estão sendo invadidas, em escala mundial, pelo rápido incremento populacional, que constitui uma das consequências diretas do desenvolvimento econômico (SOUZA; SUGUIO, 2003).

Dessa forma, as linhas de praia, sobretudo as com bases litológicas arenosas, representam indubitavelmente uma área propícia a problemas de erosão. Esses problemas decorrentes da erosão costeira também vêm sendo observados em diferentes locais do mundo, o que faz da questão um fenômeno de natureza global.

De acordo com Addad (1997), a linha de pesquisa mais disseminada defende que a principal causa dos processos erosivos nas zonas costeiras advém em função da subida global do nível do mar, responsabilizando o efeito estufa e, consequentemente, o aumento da temperatura do planeta, da ordem de 0,5 o $\mathrm{C}$ nos últimos 100 anos, como principais causadores desse fenômeno.

Segundo Muehe (2006), entre as causas mais frequentes da erosão ou progradação costeira, está a alteração no volume de sedimentos que são carregados paralelamente à linha de costa. Outra abordagem que tem sido amplamente observada nos últimos anos aponta a intervenção antrópica nos mecanismos que suprem de sedimento os ambientes marinhos, como fato que agrava e influi mais intensamente na dinâmica erosiva das orlas praiais.

Nessa perspectiva, Muehe (2006) aponta que, à medida que aumenta a ocupação do litoral, principalmente nas proximidades das grandes cidades, aumentam, também, os riscos de erosão. Já Faria (2005) concluiu que, no Brasil: 
As praias que estão sendo erodidas têm como consequência causas antrópicas ou causas naturais e até mesmo uma combinação das duas, mas não indicam uma transgressão marinha geral. Se realmente o nível do mar estiver subindo, como postulam muitos europeus e americanos, o efeito ainda não é visível na costa brasileira.

A alegação de Faria (2005) decorre de dados obtidos a partir do monitoramento de 19 praias de regiões distintas do litoral brasileiro, nas quais foi possível observar que, durante quatro décadas, as praias analisadas não sofreram mudanças no perfil praial. Tal constatação é digna de ser observada, pois, na Ponta do Seixas, as intervenções antrópicas têm se mostrado como principal agravante da degradação da paisagem.

\section{MATERIAL E MÉTODO}

Para desenvolvimento deste trabalho, foi adotada a linha metodológica proposta por Libault (1971), o qual definiu os seguintes níveis de análise:

- Compilatório: coleta e compilação de dados pertinentes à pesquisa, neste caso, imagens de satélite, registros fotográficos e mapas.

- Correlatório: etapa de comparações das informações, visando estabelecer correlações significativas ao desenvolvimento do trabalho.

- Semântico: etapa onde as verificações anteriores passam por um processo de transformação que favorecem a tomada de decisões lógicas.

- Normativo: quando os resultados são demonstrados em forma de modelos da realidade, de planejamento, caracterização ambiental, entre outros.

\section{LOCALIZAÇÃO DA ÁREA DE ESTUDO}

A Ponta do Seixas (coordenadas 7ำ'S e 34ㄴㄱ'O) está situada na Praia do Seixas, porção extremo-leste do litoral brasileiro, na cidade de João Pessoa, capital do estado da Paraíba (Figura 01), representa o marco geográfico, cujos limites são definidos ao sul pela Praia da Penha e ao norte pela Praia do Cabo Branco, esta última abriga a mais ilustre falésia do litoral paraibano, a Falésia do Cabo Branco, que, curiosamente, tem sido, muitas vezes, confundida incorretamente por turistas, e até pela população regional, como sendo o ponto mais oriental das Américas. 


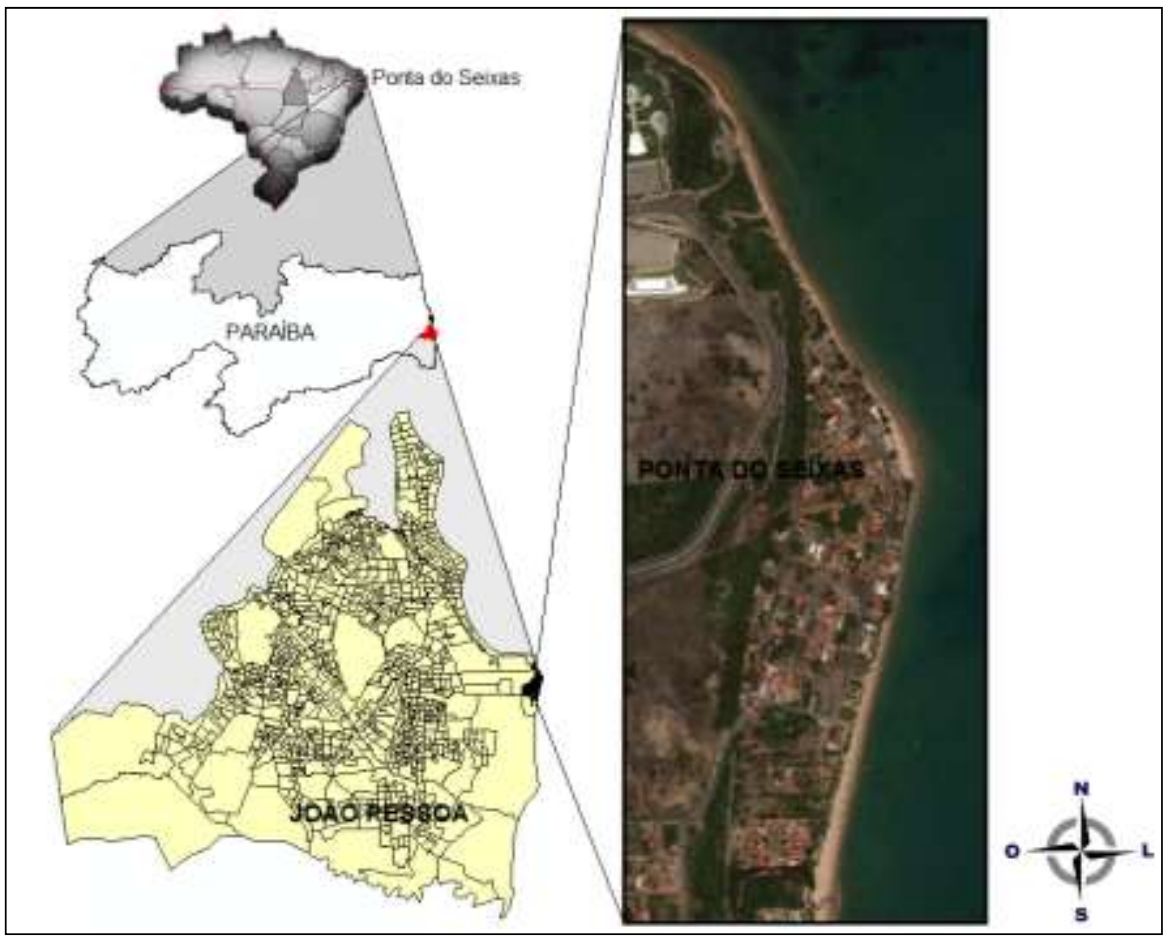

FIGURA 01: Localização geográfica da Ponta do Seixas.

Fonte: Alexandre dos Santos Souza (2014).

\section{- Aspectos atmosféricos}

O clima predominante na área estudada é o tropical quente e úmido típico do litoral, com umidade do ar relativamente alta (média de $80 \%$ ). As chuvas ocorrem com uma pluviosidade média anual que varia entre 1.400 e $1.800 \mathrm{~mm}$ por ano. São mais regulares durante o outono e inverno entre os meses de abril a julho, e, no restante do ano, o sol é abundante, com temperaturas mínimas de $22^{\circ} \mathrm{C}$ e máximas que chegam a pouco mais que $30^{\circ} \mathrm{C}$, de acordo com dados do INPE (2014).

Segundo Neves, Manso e Neves (2010, p. 59), os principais sistemas de circulação atmosférica que atuam na área são: "a Massa Equatorial Atlântica (MEA), a Zona de Convergência Intertropical (ZCIT), a Frente Polar Atlântica (FPA) e as correntes perturbadas de leste - ondas de Leste (EW)", onde predomina o ar dos alísios de SE.

\section{- Caracterização geomorfológica}

A Ponta do Seixas é uma unidade morfológica litorânea presente no compartimento geomorfológico costeiro que forma o arcabouço litoestratigráfico que compõe a Formação Barreiras. O material sedimentar da região estudada é composto por sedimentos arenoargilosos mal consolidados (FURRIER; ARAÚJO, MENESES, 2006) advindos basicamente da atuação dos agentes exógenos sobre as rochas do embasamento cristalino, situado no interior do continente.

Muehe (2006) defende que a principal fonte de reposição sedimentar dessa região é a plataforma continental interna, que, no caso em questão, é considerada estreita. 
Outro aspecto interessante é apontado por Addad (1997), para o qual a interferência humana nos suprimentos sedimentares das praias aumentou dramaticamente nas últimas décadas, fato que pode ser considerado como fator que desequilibra o perfil das praias.

A Ponta do Seixas está inserida na Baixada Litorânea, que é compreendida por uma forma de relevo plana constituída de sedimentos recentes do Quaternário, que ocupa as cotas mais baixas da orla marítima, representada pelas praias e áreas baixas de restingas litorâneas. Essa unidade é definida por Suguio (1998) como planície de baixo gradiente que margeia corpos de água de grandes extensões, como o mar ou oceano, representado habitualmente por faixas de terra recentemente emersas, compostas de sedimentos marinhos e fluviomarinhos, em geral de idade quaternária.

Para Neves, Manso e Neves (2010), os aspectos dos sedimentos da face praial da zona costeira estudada mostraram predominância de sedimentos finos pobremente selecionados, principalmente nos locais de erosão mais crítica, como é o caso da Praia do Seixas, que apresenta um ambiente com remoção contínua da partícula fina por corrente de fundo.

Um aspecto importante da geomorfologia da área é a proximidade entre o Baixo Planalto Costeiro e a planície costeira, sendo que esta última, no caso específico da Praia do Seixas, apresenta uma largura média aproximada de $250 \mathrm{~m}$ nos trechos mais espaçosos.

A plataforma continental é resultante de espessas bacias sedimentares tectônicas, que receberam milhares de metros de sedimento marinho durante a separação de África e Brasil, por meio dos grandes movimentos tectônicos de placas (AB'SABER, 2005).

É importante ressaltar que uma planície costeira corresponde a uma forma de relevo onde os processos de deposição são superiores aos de desgaste ou dissecação da paisagem. Isso significa dizer que a verdadeira planície é uma forma de relevo relativamente recente (GUERRA; GUERRA, 2006).

As planícies podem ter diversas classificações (marítimas, continentais, inundação, lacustre, deltaica, dentre outras). No caso particular da área estudada, tem-se uma planície litorânea configurando um palco onde processos naturais e antrópicos têm modelado significativamente a morfologia praial, produzindo uma paisagem extremamente suscetível e vulnerável a riscos socioambientais.

Entre as unidades geomorfológicas que delimitam a porção que abrange a Ponta do Seixas, estão: o rio do Cabelo ao sul, cuja desembocadura encontra-se degradada pela presença de construções de casas, principalmente no leito norte do canal; e a Falésia do Cabo Branco ao norte, a qual, em virtude dos sucessivos desmoronamentos em sua encosta, tem passado por períodos rotineiros de intervenção ao acesso de seu perímetro (Figura 02). 

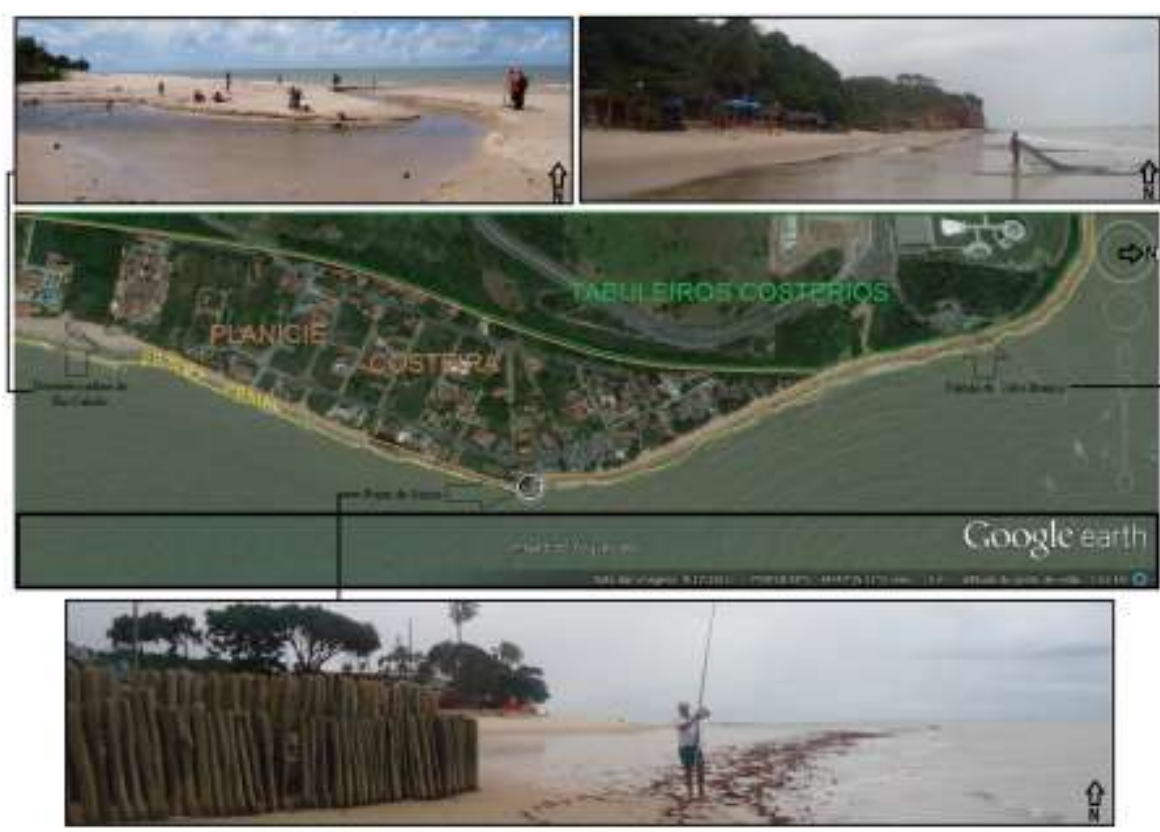

FIGURA 02: Principais unidades morfológicas presentes nas imediações da área de estudo. Fonte: Alexandre dos Santos Souza (2014); Google (2014).

Na porção marinha do antepraia da porção que abrange a Ponta do Seixas, há presença de beach rocks. Essa característica influencia significativamente na dissipação das ondas, que, na área em questão, possuem altura média de 0,5 metros, mesmo nas marés altas.

Os beach rocks são indícios de paleopraias, fator que comprova o quanto os ambientes marinhos são dinâmicos e já sofreram alterações ao longo do tempo geológico recente. Para Muehe (2006) e Ab'Saber (2005), essas formações formam setores de intensa atividade biogênica, onde se instalam grandes colônias de corais formando barreiras paralelas à linha de praia, o que influencia significativamente no clima das ondas.

É importante ressaltar, também, que as ondas atuam como os principais agentes modeladores do prisma praial, e que, no litoral paraibano, são registradas marés que oscilam entre as amplitudes de -0,1 m (micro maré) e máximas de 2,7 m, conforme dados apresentados pela Diretoria de Hidrografia e Navegação da Marinha do Brasil (2012).

Dessa forma, considerando que uma zona costeira é um ambiente muito dinâmico, frágil e fácil de sofrer alterações em seu equilíbrio, é importante observar, também, que a dinâmica responsável pelo comportamento das praias inicia sua atuação na base da antepraia (shoreface), a qual representa o limite externo da camada limite da costa (Figura 03), e que, dependendo do clima de ondas, essa camada se estenderá a profundidades de uma a duas dezenas de metros, tendo a praia como perímetro mais interno (CALLIARI et al., 2003, p. 64). 


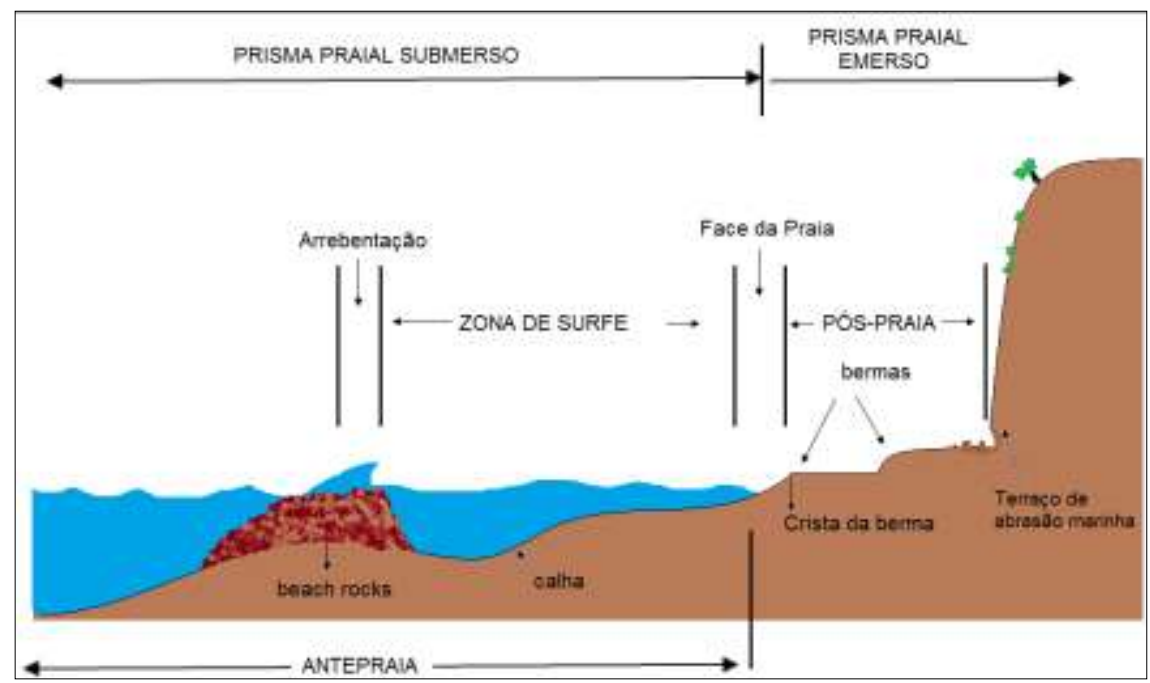

FIGURA 03: Perfil esquemático da morfologia onshore e offshore da área. Fonte: Alexandre dos Santos Souza (2015).

\section{RESULTADOS E DISCUSSÃO}

No que tange aos processos erosivos ocorridos na linha de costa estudada, foi possível averiguar um processo natural de desgaste que se agrava em áreas onde ocorrem pontões e enseadas. No caso da Ponta do Seixas, há uma incidência maior de erosão durante as marés altas, quando ocorre um maior contato de ondas refratadas na praia.

Esses processos têm sido visivelmente intensificados em decorrência de uma série de construções impróprias inseridas a partir na faixa limítrofe da berma em trechos onde se faz sentir forte influência da maré, e que estão ocupando indevidamente a zona de pós-praia.

Na extremidade sul do pontal que confina a Ponta do Seixas, uma extensa barreira de quebra-mar, erguida para proteger residências construídas na orla do pós-praia (Figura 04), demonstra estar ligada diretamente às mudanças da dinâmica de aporte e troca sedimentar na praia.

Como resultado, é percebida uma notável alteração na linha de praia que segue para o norte no trecho onde ocorre a saliência do pontal (Figura 04 b/c). A erosão nesse trecho é extremamente acentuada e já danificou significativamente a infraestrutura de casas, bares, estacionamento público e parte da desembocadura do sistema de galerias fluviais da área. 


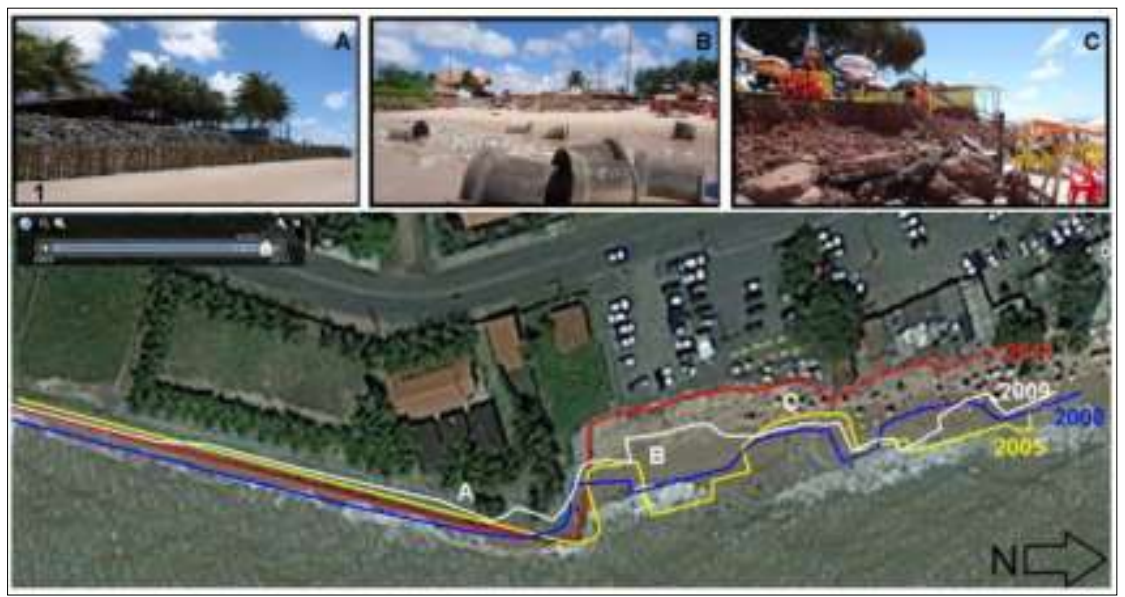

FIGURA 04: As linhas coloridas foram delimitadas respeitando os pontos exatos da linha de praia em que estavam e estão construídos bares e casas na orla que abrange a Ponta do Seixas. Como parâmetro, utilizaram-se as imagens do Google Earth disponíveis entre 2005 e 2011. As fotografias A, B e C datam de setembro de 2012. Fonte: Alexandre dos Santos Souza (2015).

Tal situação atesta o quanto a paisagem local carece de planejamento técnico. Prova disso é o material utilizado na construção do quebra-mar, onde são erguidas barreiras de contenção feitas com estacas de madeira e rochas sedimentares (predominantemente calcário) na zona limítrofe da berma (Figura 05).

Vale ressaltar que a utilização de rocha calcária é um procedimento inadequado para obras de contenção em orlas costeiras, uma vez que sua composição cárstica favorece a dissolução química, processo que, em decorrência da dinâmica imposta pela atmosfera costeira, se torna consideravelmente acelerado, fazendo-se necessária a reposição do material periodicamente, em virtude do desgaste provocado pelos fatores exógenos atuantes na área.

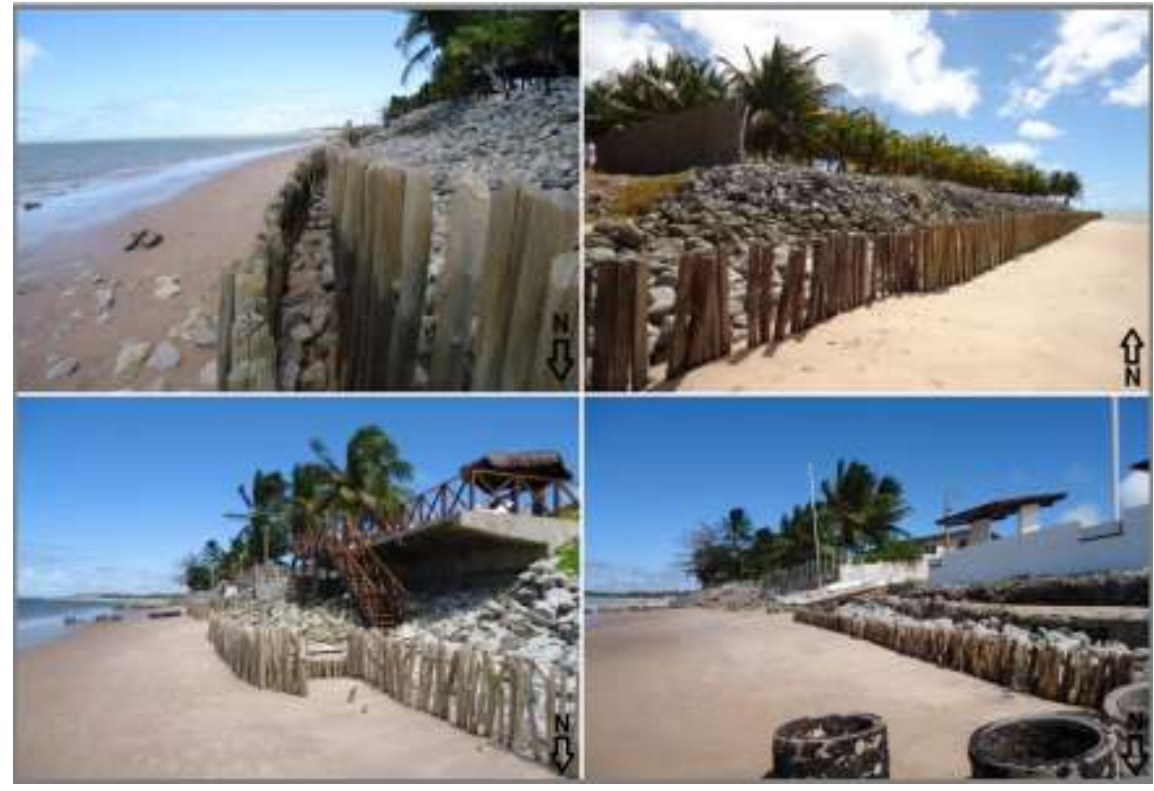

FIGURA 05: Aspectos dos arrimos construídos em imóveis residenciais na adjacência sul da Ponta do Seixas. 
Fonte: Alexandre dos Santos Souza (2015).

\section{- Análise da área frente à legislação ambiental}

No escopo de compreender a situação ambiental da área estudada, torna-se relevante analisar o meio físico à luz de normas regulamentares instituídas que proponham a preservação do meio ambiente, bem como o estabelecimento humano no espaço geográfico. Principalmente porque, no litoral do brasileiro, são comuns os problemas que se acentuam em função da falta de fiscalização do poder público no que tange à ocupação urbana do litoral, o que, muitas vezes, resulta em degradação estética e contaminação por lixo e esgotos da orla e do ambiente marinho.

Por essas razões, torna-se necessário observar alguns parâmetros da Lei no 6.938/1981 (Política Nacional do Meio Ambiente), no intuito de compreender se na área estudada existe alguma forma plausível de gerenciamento da zona costeira.

Conforme disposto no artigo 2 으 da Lei no 6.938/1981, a Política Nacional do Meio Ambiente tem por objetivo a preservação, melhoria e recuperação da qualidade ambiental propícia à vida, visando assegurar, no país, condições ao desenvolvimento socioeconômico, aos interesses da segurança nacional e à proteção da dignidade da vida humana (BRASIL, 1981).

Nessa perspectiva, foram enfatizados os seguintes princípios que constam nos parágrafos regulamentadores da mesma lei: IV - proteção dos ecossistemas, com a preservação de áreas representativas; VII - acompanhamento do estado da qualidade ambiental; IX proteção de áreas ameaçadas de degradação; $X$ - educação ambiental a todos os níveis do ensino, inclusive à educação da comunidade, objetivando capacitá-la para participação ativa na defesa do meio ambiente.

Dessa forma, considerando o fato de que a faixa de pós-praia da Ponta do Seixas e sua adjacência norte e sul encontram-se sobre forte intervenção antrópica, sobressai-se notória possibilidade de ser esse um trecho que bem exemplifica, no que tange aos itens supracitados da Lei da Política Nacional do Meio Ambiente, um espaço onde as normas legais de planejamento ambiental não foram respeitadas, contribuindo, assim, com o processo de degradação da paisagem da área.

Tais conclusões avigoram-se com o artigo 3ำ da mesma lei, que define como degradação da qualidade ambiental a alteração adversa das características do meio ambiente (inciso II) e que de alguma forma resultem em atividades que criem condições adversas às atividades sociais e econômicas, e afetem desfavoravelmente a biota (conforme alíneas " $b$ " e " $c$ " do inciso III).

A porção estudada, conforme observado na Figura 04 e 05, apresenta uma planície costeira onde a linha de pós-praia se encontra ocupada por uma quantidade significativa de construções civis (casas, bares e associações recreativas) que, de acordo com as aferições realizadas, infringem a artigos da Lei no 7.661/1988, do Plano Nacional de Gerenciamento Costeiro (PNGC), uma vez que, conforme o artigo 10 dessa lei:

As praias são bens públicos de uso comum do povo, sendo assegurado, sempre, livre e franco acesso a elas e ao mar, em qualquer direção e sentido, ressalvados os trechos 
considerados de interesse de segurança nacional ou incluídos em áreas protegidas por legislação específica (BRASIL, 1988).

A partir do que expõe o artigo supracitado, tem-se, na área, total descumprimento da legislação vigente que regula a ocupação do acrescido de marinha da União, fato comprovado por meio dos registros de campo efetuados na área, uma vez que, conforme o $\S 1$ 10 do artigo 10: "Não será permitida a urbanização ou qualquer forma de utilização do solo na Zona Costeira que impeça ou dificulte o acesso assegurado no caput deste artigo".

Nessa perspectiva, Muehe (2006) elenca diversos critérios que estabelecem limites para gerenciamento das orlas das praias, principalmente àquelas onde predominam sedimentos mal consolidados, comuns a Formação Barreiras. Para o autor, é essencial que, na fixação de zonas de proteção nas praias, seja considerada a tendência evolutiva (tempo geológico e cronológico), uma vez que esses ambientes são instáveis e dinâmicos e, por isso, deve ser inibido qualquer tipo de construções, principalmente aquelas nos perímetros susceptíveis ao efeito da transposição das ondas e com balanço sedimentar negativo.

No caso específico da Praia do Seixas, sendo esta uma zona costeira onde estão congregadas feições de alto grau de instabilidade (pontal, desembocadura de rio e falésia de arenito) ressalta-se a necessidade de ser restabelecida uma faixa mínima de proteção e manutenção da estética da paisagem semelhante à proposta por Muehe (2006) (Figura 06) ou mesmo que esteja amparada nos artigos das supracitadas leis.

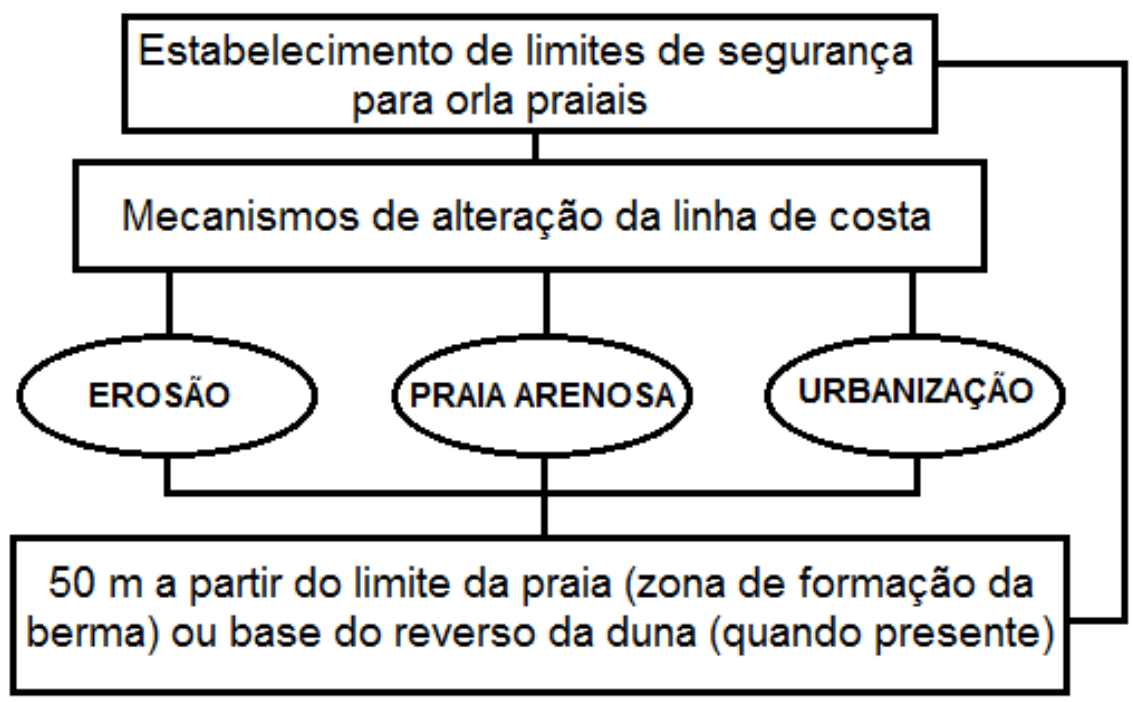

FIGURA 06: Sessão esquemática elabora a partir da proposta de Muehe (2006). Fonte: Adaptado de Muehe (2006).

Dessa forma, a partir dos pressupostos técnicos apresentados, foi definida a seguinte situação do trecho que abarca a Ponta do Seixas:

Pós-praia estreita e intensamente ocupada em decorrência do processo de urbanização, configurando um cenário visivelmente afetado pela erosão provocada pela abrasão das preamares de sizígias.

Degradação da desembocadura do rio do Cabelo (ao sul do pontal), evidenciando a grave interferência antrópica, principalmente na margem norte do canal. 
Construção de arrimos ao sul do pontal, sem qualquer evidência de planejamento e utilizando material inadequado, constituído por blocos de calcário e estacas de madeira na área de berma, fato que tem agravado ainda mais o equilíbrio dinâmico da face praial e degradado a paisagem.

Orla costeira bordejada por construções de casas, bares e clubes recreativos, servindo como contenção aos sedimentos que deveriam ser depositados naturalmente na praia pela ação gravitacional existente, levando em consideração a proximidade com os trechos escarpados dos tabuleiros litorâneos.

Destruição de estruturas artificiais construídas sobre a face praial e início do pós-praia, provocada durante as marés altas.

Só para fins de comparação, as previsões apontadas pelo Plano de Gerenciamento Costeiro, elaborado ainda em 2004 pela gestão pública municipal, previam uma forte tendência de ocupação de áreas de uso comum à beira mar por barracas, bares, residências e arrimos, a maioria em desacordo com critérios estabelecidos pela legislação municipal (Figura 07).
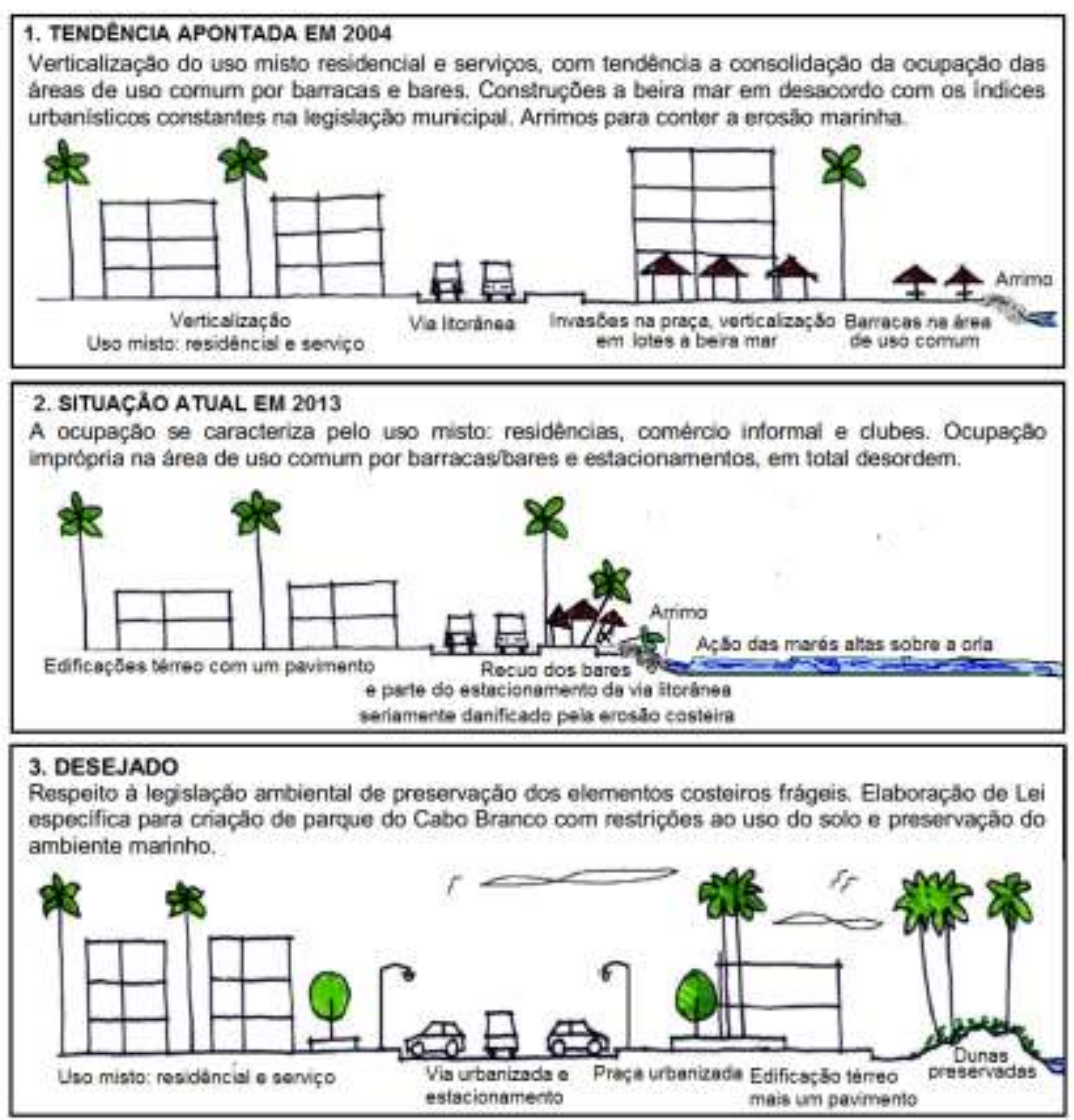

FIGURA 07: Croquis esquemáticos da área.

Fonte: adaptado de João Pessoa (2004).

A atual paisagem que configura a Ponta do Seixas, como em outros trechos da orla marítima de João Pessoa, é resumo de anos de ingerência e falta de aplicação de medidas adequadas de uso e ocupação do solo. Prova disso é o agravamento dos trechos de extrema vulnerabilidade na área, fato comprovado nas imagens registradas. 


\section{CONCLUSÃO}

Como resultado final deste trabalho, conclui-se que o processo de ocupação do espaço costeiro que abrange a Ponta do Seixas e suas adjacências traz consigo fortes implicações que têm como saldo: degradação da paisagem; ausência de planejamento no uso do solo; e ocupação desordenada da orla praial por infraestruturas inadequadas em áreas de risco.

Destarte, faz-se imperativa a necessidade de soluções eficazes que visem mitigar os efeitos da deterioração em que se encontra essa zona costeira, permitindo assegurar, de maneira efetiva, uma ocupação adequada e sem maiores danos à sociedade e ao meio ambiente. Para tanto, será imprescindível que tais soluções aconteçam por intermédio de uma ação integradora entre a sociedade e poder público, em que os esforços técnicos, financeiros e humanos sejam conjugados, a fim de conter os impactos causados em um ambiente consideravelmente frágil, como é a zona praial.

Em suma, deve-se ressaltar que tais medidas sejam implantadas a fim de promover a recuperação e a preservação desse ambiente, uma vez que a análise da área demonstrou uma série de consequências socioeconômicas negativas em função da falta de planejamento e gerenciamento do solo local, fazendo-se necessária, assim, a intervenção por parte dos órgãos públicos responsáveis pela fiscalização desse bem público, a fim de promover um ordenamento adequado do espaço em questão, considerando sua vulnerabilidade física e a importância turística da paisagem que abarca a Ponta do Seixas.

\section{BIBLIOGRAFIA}

AB'SABER, A. N. Litoral do Brasil/Brazilian coast. São Paulo, Metalivros, 2005.

ADDAD, J. Alterações fluviais e erosão costeira. Revista Brasileira de Recursos Hídricos, v. 2, n. 2, p. 21-44, jul./dez. 1997.

BRASIL. Lei no 6.938, de 31 de agosto de 1981. Dispõe sobre a Política Nacional do Meio Ambiente, seus fins e mecanismos de formulação e aplicação, e dá outras providências. Diário Oficial da República Federativa do Brasil, Brasília, DF, 2 set. 1931. Disponível em: <http://www.planalto.gov.br/ccivil 03/leis/l6938.htm>. Acesso em: 22 set. 2012.

BRASIL. Lei no 7.661, de 16 de maio de 1988. Institui o Plano Nacional de Gerenciamento Costeiro e dá outras providências. Diário Oficial da República Federativa do Brasil, Brasília, DF, 18 maio 1988. Disponível em: <http://www.planalto.gov.br/ccivil_03/leis/l7661.htm>. Acesso em: 22 set. 2012.

BRASIL. Marinha do Brasil. Diretoria de Hidrografia e Navegação. Disponível em: <https://www.mar.mil.br/dhn/dhn/index.html>. Acesso em: 13 set. 2012.

CALLIARI, L. J.; MUEHE, D.; HOEFEL, F. G.; TOLDO JR., E. E. Morfodinâmica praial: uma breve revisão. Revista Brasileira de Oceanografia, n. 51, p. 63-78, 2003.

FARIA, A. P. Eustasia global e a realidade do litoral brasileiro. Revista Brasileira de Geomorfologia, Ano 6, n. 2, 2005. 
FURRIER, M.; ARAÚJO; M. E.; MENESES, L. F. Geomorfologia e tectônica da Formação Barreiras no estado da Paraíba. Geol. USP Sér. Cient., São Paulo, v. 6, n. 2, p. 61-70, out. 2006.

GOOGLE. Google Earth. Disponível em: <http://www.google.com.br/intl/pt-BR/earth/>. Acesso em: 10 abr. 2014.

GUERRA, A. T.; GUERRA, A. J. T. Novo dicionário geológico-geomorfológico. 5. ed. Rio de Janeiro: Bertrand Brasil, 2006.

INPE - INSTITUTO NACIONAL DE PESQUISAS ESPACIAIS. Previsão do tempo para João Pessoa. Disponível em: <http://www.cptec.inpe.br/cidades/tempo/231>.

JOÃO PESSOA. Prefeitura Municipal. Proposta do Plano de Gerenciamento Costeiro de João Pessoa. João Pessoa, 2004.

LIBAULT, A. Os quatro níveis da pesquisa geográfica. Métodos em Questão, São Paulo: Instituto de Geografia (USP), n. 1, p. 1-14, 1971.

MUEHE, D. (Org.). Erosão e progradação no litoral brasileiro. Brasília: MMA, 2006.

NEVES, S. M.; MANSO, V. A. V.; NEVES, M. M. Estudo da mineralogia, textura, densidade e componentes bióticos das areias de praia e sua relação com a dinâmica praial do litoral do estado da Paraíba. Revista de Geografia. Recife: UFPE - DCG/NAPA, v. especial VIII SINAGEO, n. 2, set. 2010.

SOUZA, C. R. G.; SUGUIO, K. The coastal erosion risk zoning and the São Paulo Plan for Coastal Management. Journal of Coastal Research, Special Issue 35, p. 530-547, 2003.

SUGUIO, K. Dicionário de geologia sedimentar e áreas afins. Rio de Janeiro: Bertand Brasil, 1998.

\begin{tabular}{ll} 
Artigo submetido em & $19 / 05 / 2015$ \\
\hline Artigo aceito em & $09 / 17 / 2015$
\end{tabular}

